\title{
PENGARUH KUALITAS FISIK (BOBOT DAN BENTUK) TELUR ITIK SUPER PEKING PUTIH (SP2-F1) TERHADAP FERTILITAS, DAYA TETAS DAN BOBOT TETAS
}

\author{
Edi Sutanto $^{1}$, Dyanovita Al-Kurnia ${ }^{2}$, Dyah Wahyuning Aspriati ${ }^{3}$ \\ ${ }^{1}$ Program Studi Peternakan Fakultas Peternakan Universitas Islam Lamongan \\ 2 dan 3 Dosen Fakultas Peternakan - Universitas Islam Lamongan \\ Jl. Veteran No. 53 Lamongan \\ e-mail: edisutanto220292@gmail.com
}

\begin{abstract}
Abstrak
Penelitian dilaksanakan pada tanggal 15 April - 13 Mei 2018 di unit penetasan telur UPT. Agri Science Technopark Fakultas Peternakan Universitas Islam Lamongan. Tujuan dari penelitian adalah untuk mengetahui pengaruh kualitas fisik (bobot dan bentuk) telur itik Super Peking Putih (SP2-F1) terhadap fertilitas, daya tetas dan bobot tetas. Hasil penelitian ini diharapkan dapat dipakai sebagai informasi bagi masyarakat dan sebagai refrensi dan perbandingan pada penelitian selanjutnya.Penelitian ini menggunakan 80 butir telur itik Super Peking Putih (SP2-F1) dengan rasio induk jantan dan betina 1:5. Penelitian ini menggunakan rancangan acak lengkap (RAL) pola tersarang (nested design) $2 \times 2$ dengan 4 ulangan dengan setiap ulangan terdiri dari 5 butir telur. Faktor ke 1 adalah bobot telur ( K: 54-64 gram dan B: 65-75 gram) dan faktor ke 2 adalah bentuk telur (lonjong (L) : indeks 70-75\% dan oval(O): indeks 76-80\%). Hasil analisis variansi menunjukkan bahwa perlakuan yang diberikan tidak mempengaruhi fertilitas dan daya tetas, tetapi berpengaruh terhadap bobot tetas.. Tidak terdapat interaksi antara bobot dan indeks bentuk telur terhadap fertilitas, daya tetas, dan bobot tetas DOD Itik Super Peking Putih (SP2-F1). Kesimpulan dari penelitian ini ialah bobot telur tidak berpengruh nyata terhadap fertilitas dan daya tetas $(P>0,05)$, tetapi berpengaruh sangat nyata terhadap bobot tetas telur itik SP2-F1 $(P<0,05)$. Sedangkan bentuk telur tidak berpengaruh nyata terhadap fertilitas, daya tetas maupun bobot tetas telur itik SP2-F1 $(P>0,05)$.
\end{abstract}

Kata Kunci : Kualitas Fisik Telur (Bobot dan Bentuk), Itik Super Peking Putih (SP2-F1),Fertilitas, Daya Tetas,Bobot Tetas.

\section{PENDAHULUAN}

Permintaan daging itik (bebek) saat ini terus naik, hal ini dapat dilihat dari banyaknya warung dan rumah makan yang menyajikan menu olahan daging itik. Data Dirjen Peternakan dan Kesehatan Hewan Kementan RI (2017) menyebutkan bahwa jumlah produksi daging itik di Indonesia mencapai 43.156 ton pada tahun 2017. Tetapi jumlah tersebut hanya mencukupi $70 \%$ pemenuhan akan kebutuhan. Kondisi pemenuhan kebutuhan tersebut masih belum terkomersialisasi dengan baik seperti pada usaha ayam pedaging.
Pemeliharaan itik di Indonesia umumnya masih secara tradisional sehingga produksinya cukup rendah. Pemeliharaan itik secara intensif harus ditunjang dengan penyediaan bibit secara berkelanjutan dan dalam jumlah yang besar. Kondisi yang ada saat ini penyediaan day old ducks (DOD) masih terbatas dan belum mencukupi untuk memenuhi kebutuhan. Kurangnya pasokan DOD yang seragam dan dalam jumlah yang besar menyebabkan kebutuhan bibit itik belum bisa terpenuhi dikarenakan belum ada pembibitan (breeding) dan penetasan (hatchery) modern dalam skala besar untuk itik. Pembibitan dan penetasan itik 
yang ada saat ini kebanyakan dimiliki oleh peternakan rakyat dan ternaknya terbatas hanya dalam skala kecil (Dewanti, et al, 2014).

Potensi produk jenis itik di Indonesia masih rendah (dengan bobot badan 1,8-2 kg per umur 3 bulan), lebih banyak didominasi itik jenis lokal (Suharno dan Amri, 2003). Sehingga mengakibatkan harga daging itik mahal. Itik Super Peking Putih (SP2-F1) adalah itik peking generasi ke-3 hasil grading up dari persilangan itik Peking jantan dengan itik Hibrida betina (Peking $x$ Mojosari). Itik Super Peking Putih (SP2-F1) memiliki pertambahan bobot badan mencapai $\geq 3 \mathrm{~kg}$ per umur 3 bulan lebih besar dari pada itik lokal yang hanya 1,8-2 kg per umur 3 bulan (Suharno dan Amri, 2003), tetapi lebih kecil dari pada itik Peking yang bisa mencapai bobot 3-4 kg per umur 3 bulan (Adzitey dan Adzitey, 2011).

Proses penetasan telur merupakan proses alami yang sangat komplek untuk menghasilkan individu baru. Hasil penetasan terbaik adalah penetasan alami dengan menggunakan induk betina, akan tetapi cara alami ini mempunyai keterbatasan dalam jumlah telur yang dapat ditetaskan per satuan waktu. Seekor induk hanya dapat mengerami telur maksimum 20 butir per periode. Oleh karena itu, penetasan dengan menggunakan mesin tetas buatan lebih sering digunakan untuk mencapai jumlah yang lebih besar dan secara komersial. Penetasan telur itik dengan menggunakan mesin tetas buatan agak lebih sulit dari telur ayam karena telur itik memerlukan tingkat kelembaban yang lebih tinggi dan kebutuhan kelembaban ini harus dipenuhi dengan akurasi yang tinggi. Telur tetas yang baik seharusnya mempunyai daya tunas (fertilitas) mencapai 9095\% dan daya tetas $70-80 \%$, dan pencapaian ini merupakan kombinasi antara kualitas induk dan kualitas mesin tetas. Telur itik memerlukan waktu 28 hari untuk menetas dengan baik (Balai Penelitian Ternak, 2011).

Daya tetas yang rendah dapat mengakibatkan kerugian bagi usaha penetasan. Daya tetas telur dipengaruhi oleh kualitas fisik dari telur tetas. Telur tetas yang berkualitas diperoleh dari program pemeliharaan itik pembibit yang baik. Kualitas fisik telur tetas dapat diukur dari bobot dan bentuk telur tetas. Telur itik Super Peking Putih (SP2-F1) berwarna putih dan hijau serta memiliki bobot dan bentuk yang beragam. Untuk mengetahui tingkat daya tetas dari telur itik Super Peking Putih (SP2-F1) maka diperlukan penelitian mengenai pengaruh kualitas fisik (bobot dan bentuk) telur itik Super Peking Putih (SP2-F1) terhadap fertilitas, daya tetas dan bobot tetas.

\section{MATERI DAN METODE}

\section{Materi Penelitian}

Penelitian ini menggunakan 80 butir telur itik Super Peking Putih (SP2-F1) dengan rasio induk jantan:betina adalah 1:5. Bahan lain yang digunakan dalam penelitian ini adalah alkohol $70 \%$ untuk sterilisasi telur dan Desinfektan untuk fumigasi mesin. Mesin tetas yang digunakan adalah mesin tetas manual dengan kapasitas 350 butir (sumber pemanas lampu dilengkapi thermostat, pembalikan manual dengan tangan) Pengaturan suhu 37-38 C dan kelembaban $65-70 \%$ Peralatan lain yang digunakan adalah timbangan analitik (untuk menimbang telur dan DOD), egg tray (untuk menyimpan telur) ,sprayer (untuk menambah kelembaban), jangka sorong (untuk mengukur indeks bentuk telur), Thermohygrometer (untuk mengukur kelembaban dan suhu mesin tetas), candler (alat teropong telur), dan nampan plastic.

\section{Metode Penelitian}

Penelitian ini menggunakan rancangan acak lengkap (RAL) pola tersarang (nested design) $2 \times 2$ dengan 4 ulangan dengan setiap ulangan terdiri dari 5 butir telur. Perlakuan yang dilakukan adalah KL : Telur Kecil (54-64 gram) dengan indeks Lonjong (70-75\%), KO : Telur Kecil (54-64 gram) dengan indeks Oval (76$80 \%$ ), BL : Telur Besar (65-75 gram) dengan indeks Lonjong (70-75\%), BO : Telur Besar (6575 gram) dengan indeks Oval (76-80\%).

\section{Variabel yang Diamati}

Variable yang diukur dalam penelitian ini adalah : fertilitas, daya tetas dan bobot tetas. 
- Fertilitas $=($ Jumlah telur fertil)/(Jumlah telur masuk) $\times 100 \%$

- Daya Tetas $=($ Jumlah telur menetas $) /($ Jumlah telur fertil) $\times 100 \%$

- Bobot tetas dihitung dengan cara menimbang DOD setelah bulu kering.

\section{Analisis data}

Data yang diperoleh dianalisis dengan analisis variansi dengan taraf siginifikasi $5 \%$ dan $1 \%$. Apabila perlakuan menunjukkan pengaruh yang nyata, selanjutnya dilakukan uji lanjut dengana Uji Beda Nyata Terkecil (BNT) (Gaspersz, (1991) dalam Mukminah, (2015)). Model matematis analisis ragam pola tersarang dua tahap (Two-Stage Nested Design) menurut Sastrosupadi (2000) dalam Mukminah, (2015) adalah:

$$
Y(i j k)=\mu+\alpha i+\beta j(i)+\varepsilon i j k
$$

Keterangan :

Yijk = Respon dari faktor bobot telur $(\alpha)$ ke-i dan faktor bentuk telur $(\beta)$ ke-j yang bersarang pada faktor bobot telur dan ulangan ke-k.

$M=$ Nilai tengah umum

$\alpha i=$ Pengaruh faktor bobot telur ke-i $(i=1,2)$

$\beta \mathrm{j}(\mathrm{i})=$ Pengaruh bentuk ke-j yang bersarang pada bobot ke-i $(j=1,2)$

$\varepsilon i j k=$ Galat percobaan oleh bobot telur $(\alpha)$ ke-i, bentuk telur $(\beta)$ ke-j yang bersarang pada bobot telur, dan ulangan ke- $\mathrm{k}$

$\mathrm{i}=$ Banyaknya faktor berat telur

$j=\quad$ Banyaknya faktor bentuk telur

$\mathrm{k}=$ Banyaknya ulangan

\section{Waktu dan Lokasi Penelitian}

Penelitian dilaksanakan di unit penetasan telur UPT. Agri Science Technopark Fakultas Peternakan Universitas Islam Lamongan pada tanggal 15 April - 13 Mei 2018

\section{HASIL DAN PEMBAHASAN}

\section{Pengaruh Perlakuan Terhadap Fertilitas Telur}

Fertilitas merupakan salah satu faktor utama yang menentukan keberhasilan dalam usaha penetasan karena hanya telur yang fertil yang dapat menghasilkan DOD.

Tabel 1. Rataan fertilitas telur itik Super Peking Putih (SP2-F1)

\begin{tabular}{llll}
\hline Bobot & Bentuk & $\begin{array}{l}\text { Total } \\
(\%)\end{array}$ & $\begin{array}{l}\text { Rataan } \\
(\%)\end{array}$ \\
\hline K & L & 340 & 85 \\
& O & 360 & 90 \\
B & L & 360 & 90 \\
& O & 360 & 90
\end{tabular}

Sumber: Data Primer yang Telah Diolah (2018)

Hasil analisis variansi menunjukkan hasil tidak berbeda nyata $(P>0,05)$ seperti tertera pada Tabel 4.2. Hal ini menunjukan bahwa bobot dan indeks telur berpengaruh tidak nyata terhadap fertilitas telur itik SP2-F1. Hal tersebut dikarenakan bobot telur yang ditetaskan sudah pada kisaran normal dan seragam, tidak terlalu besar dan tidak terlalu kecil yaitu dalam kisaran 54-75 gram. Begitu juga dengan indeks bentuk telur yang digunakan masih kisaran normal yaitu dalam kisaran $70 \%-80 \%$. Hal tersebut didukung oleh Dewanti, et al, (2014) yang menyatakan bahwa bobot telur tidak memberikan pengaruh yang nyata terhadap Fertilitas. Serta Hermawan, (2000) dalam Ummah, (2017), yang menyatakan bahwa indeks bentuk telur 70\% - 79\% merupakan kisaran indeks bentuk telur yang normal.

Suprijatna, et al, (2005) dalam Jumbriyadi, (2017) menyatakan bahawa ada beberapa faktor yang menentukan fertilitas. Faktor tersebut adalah umur ternak, sex ratio, jarak waktu kawin sampai bertelur, pakan dan musim. Dalam penelitian ini, fertilitas telur itik SP2-F1 cukup tinggi, yaitu 80-100 \%. Hal tersebut dikarenakan induk yang digunakan sudah berumur 8 bulan lebih sehingga telur itik sudah siap untuk ditetaskan. Fertilitas juga 
dipengaruhi oleh rasio jantan betina sehingga untuk memastikan telur yang diproduksi terbuahi maka kira-kira 1 pejantan sebaiknya mengawini 5 - 10 betina (King'ori, (2011) dalam Ummah,(2017)). Perbandingan antara jantan dan betina yang digunakan dalam penelitian ini juga sudah cukup yaitu $1: 5$ sehingga jumlah pejantan cukup untuk mengawini betina. Pakan yang diberikan adalah pakan ayam petelur pabrikan sehingga pakan sudah cukup untuk memenuhi kebutuhan itik petelur.Uji $\mathrm{pH}$ yang diamati dalam penelitian ini adalah menunjukan nilai $\mathrm{pH} 4,1$ dengan kategori silase batang pisang memiliki kualitas baik. Menurut MacAulay (2004) bahwa kualitas silase digolongkan menjadi empat kriteria $\mathrm{pH}$ yaitu baik sekali

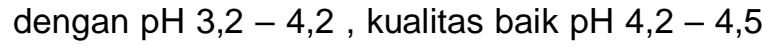
dan kualitas buruk $\mathrm{pH}>4,8$. Menurut Kung dan Nylon (2001) bahwa pH merupakan salah satu penentu dari keberhasilan fermentase.

\section{Pengaruh Perlakuan Terhadap Daya Tetas}

Daya tetas merupakan salah satu faktor utama yang menentukan keberhasilan dalam usaha penetasan karena semakin tinggi daya tetas maka semakin banhyak DOD yang dihasilkan dan begitu juga sebaliknya semakin rendah daya tetas maka semakin rendah pula DOD yang dihasilkan. Daya tetas dihitung dengan membandingkan jumlah telur yang menetas dengan jumlah seluruh telur yang fertil. Semakin tinggi jumlah telur yang fertil dari jumlah telur yang ditetaskan akan dihasilkan persentase daya tetas yang tinggi pula (North dan Bell,(1990) dalam Dewanti, et al, (2014)).

Tabel 2. Rataan daya tetas telur itik Super Peking Putih (SP2-F1)

\begin{tabular}{llll}
\hline Bobot & Bentuk & Total (\%) & $\begin{array}{l}\text { Rataan } \\
(\%)\end{array}$ \\
\hline K & L & 260 & 65,00 \\
& O & 295 & 73,75 \\
B & L & 265 & 66,25 \\
& O & 340 & 85,00 \\
\hline
\end{tabular}

Sumber: Data Primer yang Telah Diolah (2018)

Hasil yang diperoleh dan setelah dianalisis variansi menunjukkan bahwa bobot telur memberikan pengaruh tidak nyata terhadap daya tetas telur $(P>0,05)$. Hal ini dikarenakan bobot telur yang ditetaskan adalah telur dengan bobot ideal yaitu dalam kisaran 54-75 gram perbutir. Hal tersebut didukung oleh Hassan et al. (2005) dalam Dewanti, et al,(2014), yang menyatakan bahwa telur yang baik untuk ditetaskan adalah telur yang tidak terlalu besar atau terlalu kecil. Bobot telur itik yang terlalu berat $(>77 \mathrm{~g})$ atau terlalu kecil $(<50 \mathrm{~g})$ dapat menyebabkan menurunnya daya tetas.

Indek bentuk telur juga memberikan pengaruh tidak nyata terhadap daya tetas telur pada penelitian ini $(P>0,05)$ seperti tertera pada Tabel 4.3. Hal ini dikarenakan indeks bentuk telur itik SP2-F1 yang digunakan masih dalam kisaran normal yaitu kisaran $70-80 \%$. Hasil penelitian ini berbeda dengan penelitian yang dilakukan oleh Ummah, et al,(2017) yang menyatakan bahwa telur dengan indeks bentuk normal menghasilkan daya tetas yang lebih tinggi dari pada telur dengan indeks bentuk lonjong mauapun bulat pada itik Magelang generasi ketiga di Satuan Kerja Itik Banyubiru. Sehingga indeks bentuk telur memeberikan pengaruh nyata terhadap daya tetas telur itik Magelang generasi ketiga.

Tidak nyatanya pengaruh perlakuan terhadap daya tetas pada penelitian ini kemungkinan juga disebabkan oleh fertilitas yang tidak berbeda nyata. Namun jika dilihat dari nilai fertilitas yang cukup tinggi baik pada masing-masing perlakuan sedangkan nilai daya tetas yang relatif rendah hal ini kemungkinan disebabkan oleh pada proses penetasannya. Beberapa faktor yang mempengaruhi tinggi rendahnya daya tetas antara lain kecermatan pada saat memilih telur yang akan ditetaskan, keadaan mesin tetas, iklim, genetik, perkawinan (inbreeding), pakan dan kondisi kandang (Rukmana,(2007) dalam Ummah, (2017)). Faktor lain yang mempengaruhi kegagalan dalam proses penetasan diantaranya yaitu penanganan saat penetasan misalnya pemutaran telur yang kurang berhati-hati (Gonzalez et al.,(1999) dalam Dewanti, et al,(2014)). Diketahui bahwa mesin tetas yang digunakan adalah mesin tetas manual dengan kapasitas 350 butir (sumber pemanas lampu 
dilengkapi thermostat, pembalikan manual dengan tangan). Pembalikan yang masih secara manual menyebabkan telur rawan akan benturan sehingga meningkatkan persentase kematian dini embrio.

Frekuensi pemutaran telur juga memengaruhi daya tetas. Penelitian Dewanti, et al, (2014) menunjukan bahwa frekuensi pemutaran telur idealnya adalah 8 kali dalam sehari. frekuensi pemutaran telur 8 kali/hari menghasilkan daya tetas tertinggi dibandingkan dengan perlakuan dengan frekuensi pemutaran 4, dan 6 kali/hari. Pada penelitian ini pemutaran telur masing-masing perlakuan hanya dilakukan 3 kali/hari. Namun keadaan ini telah memenuhi standar seperti yang dikemukakan oleh Setioko, (1992) dalam Lestari, (2012), yang menyatakan bahwa pemutaran telur itik dilakukan 3 atau 5 kali sehari dengan interval waktu yang sama.

\section{Pengaruh Perlakuan Terhadap Bobot Tetas}

Bobot tetas merupakan bobot ternak sesaat setelah menetas (Septiwan, (2007) dalam Ummah, (2017)), Bobot tetas dihitung dengan cara menimbang DOD setelah bulu kering. Ada hubungan yang sangat nyata antara bobot telur dengan bobot tetas, semakin tinggi bobot telur yang ditetaskan akan menghasilkan bobot tetas yang lebih besar (Hermawan, (2000) dalam Dewanti, et al, (2014))

Tabel 2. Rataan bobot tetas telur itik Super Peking Putih (SP2-F1)

\begin{tabular}{llll}
\hline Bobot & Bentuk & Total (\%) & $\begin{array}{l}\text { Rataan } \\
(\%)\end{array}$ \\
\hline K & L & 162,50 & $40,63^{\mathrm{a}}$ \\
& $\mathrm{O}$ & 164,58 & $41,15^{\mathrm{ab}}$ \\
$\mathrm{B}$ & $\mathrm{L}$ & 185,33 & $46,33^{\mathrm{c}}$ \\
& $\mathrm{O}$ & 187,00 & $46,75^{\mathrm{ca}}$ \\
\hline
\end{tabular}

Sumber: Data Primer yang Telah Diolah (2018)

Hasil yang diperoleh dan setelah dianalisis variansi menunjukkan bahwa bobot telur berpengaruh sangat nyata terhadap bobot tetas DOD $(P<0,05)$. Bobot telur 65-75 gram menghasilkan rerata bobot DOD yang paling berat yaitu sebesar 46,86 gram dan bobot telur terendah terdapat pada telur dengan berat 5464 gram yaitu 40,20 gram.

Sudaryani dan Santoso (1994), menyatakan bahwa bobot telur tetas merupakan faktor utama yang memengaruhi bobot tetas, selanjutnya dinyatakan bobot tetas yang normal adalah $2 / 3$ dari bobot telur dan apabila bobot tetas kurang dari hasil perhitungan tersebut maka proses penetasan bisa dikatakan belum berhasil. Semakin besar bobot telur maka bobot DOD yang dihasilkan juga semakin besar. Hal ini disebabkan nutrien yang terkandung dalam telur besar tentunya lebih banyak dibandingkan telur kecil, sehingga lebih banyak pula yang diserap ke tubuh embrio. Telur banyak mengandung nutrien seperti vitamin, mineral, dan air yang dibutuhkan untuk perkembangan embrio selama inkubasi, serta digunakan juga sebagai cadangan makanan (Pattison, (1993) dalam Dewanti, et al, (2014)).

Sedangkan indeks bentuk telur berpengaruh tidak nyata terhadap bobot tetas $(P>0,05)$ seperti tertera pada Tabel (Tabel 4.5). Hal tersebut sesuai dengan penelitian Mahi. (2013) dalm Ummah, et al,(2017) yang menyatakan bahwa Indeks bentuk telur berpengaruh tidak nyata $(P>0,05)$ terhadap bobot tetas.

Karena bobot telur menunjukkan adanya perbedaan yang sangat nyata terhadap bobot tetas, maka perlu dilakukan uji lanjut Uji Beda Nyata Terkecil (BNT) untuk mengetahui ada tidaknya perbedaan antar tiap perlakuan (Gaspersz, (1991) dalam Mukminah, (2015)). Setelah dilakukkan uji lanjut uji Beda Nyata Terkecil (BNT) didapatkan hasil seperti tertera pada Tabel (Tabel 4.6). Hasil rataan dari perlakuan yang diikuti oleh huruf yang sama menunjukan tidak berbeda nyata menurut BNT5\%. Sedangkan hasil rataan dari perlakuan yang diikuti oleh huruf yang berbeda menunjukan perberbedan nyata menurut BNT5\%. Perlakuan diikuti oleh huruf yang berbeda, sehingga dapat disimpulkan bahwa perlakuan telur dengan bobot 54-64 gram (K) berbeda nyata dengan perlakuan telur dengan bobot 65-75 gram (B). 


\section{DAFTAR PUSTAKA}

Adzitey, F.and Adzitey, SP., 2011. Duck Production Has a Potential To Reduce Poverty Among Rural Households in Asian Communities - A Mini Review. J.World's Poult. Res. 1 (1) : $7-10$.

Balitnak, 2011. Itik Hibrida Master Sebagai Bibit Niaga Itik Petelur Unggul. Jurnal. Balai Penelitian Ternak, Bogor.

Dewanti, R., Yuhan, dan Sudiyono. 2014. Pengaruh Bobot Dan Frekuensi Pemutaran Telur Terhadap Fertilitas, Daya Tetas, Dan Bobot Tetas Itik Lokal. Jurnal. Fakultas Pertanian, Universitas Sebelas Maret Surakarta.

Direktorat Jenderal Peternakan. 2017. Statistik Peternakan dan Kesehatan Hewan 2017/ Livestock and Animal Health Statistics 2017. Direktorat Jenderal Peternakan. Departemen Pertanian RI, Jakarta.

Lestari, Ana Sri. 2012. Pengaruh Pengolahan Penetasan Terhadap Fertilitas dan Daya Tetas Telur Itik Mojosari. Skripsi. Fakultas Pertanian, Universitas Lampung. Bandar Lampung.

Sudaryani, T. H, dan Santoso. 1994. Pembibitan Ayam Ras. Penebar Swadaya. Jakarta

Suharno, B dan K. Amri. 2003. Beternak Itik Secara Intensif. Cetakan kedelapan. Penebar Swadaya. Jakarta

Ummah, Siti Rohmatul, 2017, Pengaruh Indeks Bentuk Telur Terhadap Fertilitas, Daya Tetas, Bobot Tetas dan Mortalitas Pada Itik Magelang Generasi Ketiga Di Satuan Kerja Itik Banyubiru. Skripsi. Fakultas Peternakan Dan Pertanian, Universitas Diponegoro Semarang. 